\title{
Displasia epitelial focal por el uso de un único cepillo dental en la familia
}

\author{
Maricela Viola-Rhenals ${ }^{\mathrm{a}}$, Zulieth López Arrieta ${ }^{\mathrm{b}}$, Manuel Escalante Fontalvo ${ }^{\mathrm{c}}$
}

\begin{abstract}
a Doctor en Ciencias mención Bioquímica, Director del Grupo de Bioquímica y Biología Celular del Cáncer, Universidad de Cartagena, Cartagena, Colombia

b Odontóloga, Joven Investigador COLCIENCIAS, Universidad de Cartagena, Cartagena, Colombia

c Odontólogo, Especialista en Estomatología y Cirugía Oral, Universidad Metropolitana de Barranquilla, Barranquilla, Colombia

Correspondencia: Maricela Viola-Rhenals

Correo electrónico: maricela.

viola@gmail.com

Recibido el 04 de junio de 2013.

Aceptado para su publicación el 21 de agosto de 2013.
\end{abstract}

\section{RESUMEN}

La hiperplasia epitelial focal es una de las patologías pertenecientes al grupo de infecciones causadas por el Virus del Papiloma Humano (VPH) relacionada con los tipos 13 y 32 . Su transmisión es por contacto directo o indirecto con secreciones infectadas, siendo su grupo poblacional predilecto los niños, cuyo riesgo es mayor si presentan en su familia condiciones de salubridad insuficiente y malas prácticas de higiene. El tratamiento depende de la evolución de las lesiones que en la mayoría de los casos se resuelven espontáneamente, por lo que es suficiente con la observación. En caso de manifestaciones más severas se puede utilizar crioterapia, cirugía y acido acético.

Palabras clave: hiperplasia epitelial focal, higiene, relaciones profesional-familia, enfermedades de la boca.

\section{ABSTRACT}

Focal epithelial dysplasia caused by the use of a sole family toothbrush.

Focal epithelial dysplasia is one of the pathologies belonging to the group of infections caused by the Human Papilloma Virus (HPV), related to types 13 and 32. It is transmitted by direct or indirect contact with infected secretions, with its preferred population group being children, whose risk is greater if inadequate health conditions and bad hygiene practices are present in the family. Treatment is dependent on the evolution of lesions, which in the majority of cases remit spontaneously, in which case, observation is sufficient. In more severe cases, cryotherapy, surgery and acetic acid can be used

Key words: Focal epithelial dysplasia, hygiene, professional-family relations, mouth diseases.

\section{INTRODUCCIÓN}

El virus del papiloma humano (VPH) se asocia en la cavidad oral a condiloma acuminado, verruga vulgar, papiloma escamoso e hiperplasia epitelial focal ${ }^{1}$, cuya presentación es más común en niños ${ }^{2}$ y en personas con inmunodeficiencia o con prácticas sexuales de alto riesgo, como lo es el sexo oral ${ }^{3}$.

Se caracteriza por la aparición de pequeñas pápulas, placas o nódulos, especialmente en la mucosa labial, mucosa bucal y lengua ${ }^{4}$. La biopsia revela hiperplasia epitelial, acantosis, extensión de las crestas epiteliales y degeneración de la capa espinosa. Los antígenos virales han sido detectados por inmunohistoquímica ${ }^{2}$, haciendo más fácil el diagnóstico diferencial de esta patología con el papiloma por mordedura, el condiloma acuminado, la papilomatosis oral de Florida, la hiperplasia epitelial difusa características de los mascadores de tabaco y las verrugas vulgares ${ }^{5}$.

El potencial maligno se limita a casos aislados y después de un tratamiento adecuado la recidiva es minima 6 .

\section{OBSERVACIONES CLÍNICAS}

Paciente de sexo masculino, de 12 años de edad, que acude a la consulta por presentar múltiples pápulas en la cavidad bucal. La madre refiere que 
hace dos meses observó dos de estas lesiones en la mucosa del labio inferior del niño y decidió tratarlas con ungüentos caseros, sin obtener resultados favorables, ya que las lesiones se multiplicaron y aumentaron de tamaño paulatinamente, extendiéndose a la mucosa de labio superior, mucosa yugal y cara dorsal de la lengua. Además, en la anamnesis se reporta que el niño proviene de un estrato socioeconómico bajo y que es habitual utilizar un único cepillo dental para toda la familia. La madre reconoce prácticas sexuales orales con más de un compañero y sin protección.

El niño no presenta alteraciones sistémicas y los exámenes hematológicos son normales. En el examen clínico de la cavidad oral se evidencian múltiples pápulas de formas redondeadas, de superficie lisa o de aspecto mirtiforme, ubicadas en mucosa labial, mucosa yugal y cara dorsal de lengua. Son de un tamaño variable, color rosado pálido, consistencia blanda a la palpación y base sésil (figuras 1 y 2). El paciente no presenta dolor.

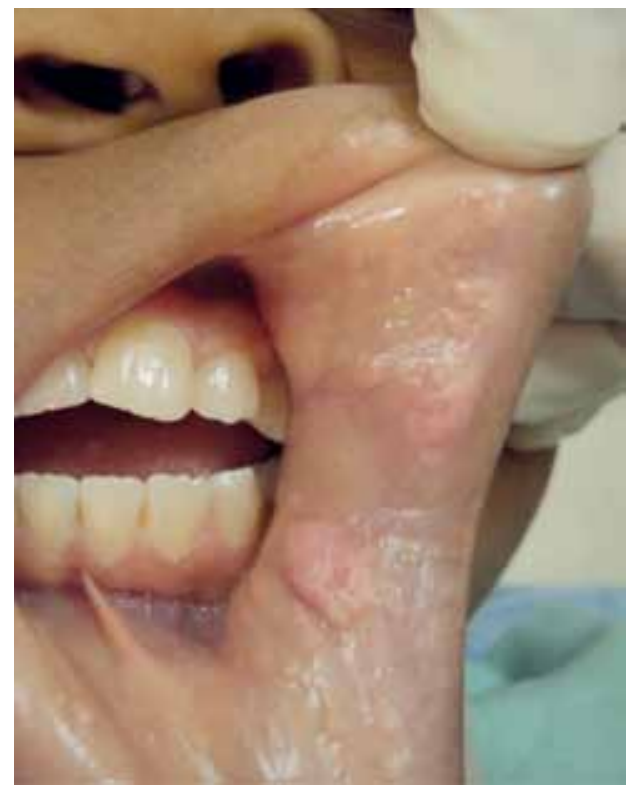

Figura 1. Múltiples pápulas de formas redondeadas, de superficie lisa o de aspecto mirtiforme ubicadas en mucosa labial y mucosa yugal

Se decide realizar biopsia para examen histológico y estudio inmunocitoquímico de PCR, que confirma el diagnostico presuntivo de enfermedad de Heck.

Las lesiones fueron tratadas con acido acético, previa limpieza de la zona e irrigación posterior con dilución de bicarbonato de sodio en agua. Las lesiones se redujeron hasta un $50 \%$ a la semana siguiente a las topificaciones.

\section{COMENTARIOS}

La relación entre la familia y el profesional sanitario, como la educación en salud, es fundamental para evitar transmisiones intrafamiliares como la producida por el $\mathrm{VPH}^{7}$. En el mundo, la publicación de casos de hiperplasia epitelial focal en niños va en aumento y se considera una población de alto riesgo, principalmente cuando su entorno es de pobreza, de escasa educación sexual y salubridad $^{8-9}$. En este caso, la trasmisión se dio de la madre al hijo, por el uso de un único cepillo dental para la familia. La literatura reporta casos de transmisión entre comunidades que presentan prácticas sexuales orales frecuentes ${ }^{3}$ y pacientes con depresión del sistema inmune, como es el caso de medicamentos supresores indicados en individuos con trasplante renal ${ }^{10}$.

Para el tratamiento se utilizó acido acético debido al gran número de lesiones, previendo que en la cirugía el postoperatorio es más traumático y doloroso. Otras opciones para tratar estas lesiones son la crioterapia, la electrocoagulación y el láser de dióxido de carbono ${ }^{4}$.

La promoción de hábitos higiénicos, educación sexual y un buen seguimiento del profesional en salud al paciente y su familia son las principales maneras para evitar que se den este tipo de inoculaciones del virus VPH, reiterando el

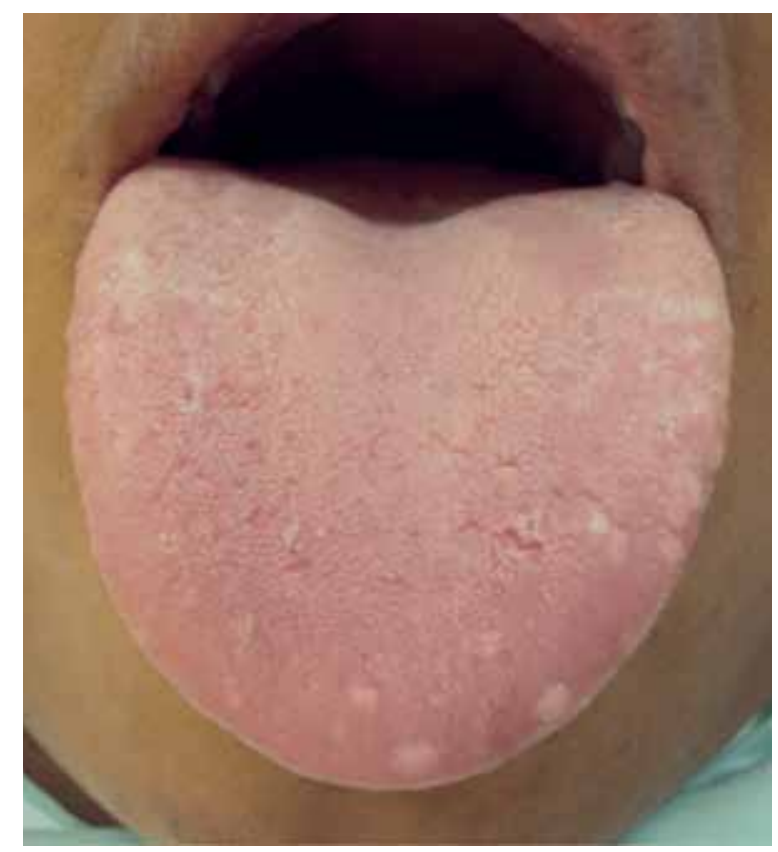

Figura 2. Pápulas multiformes, blancas, ubicadas en cara dorsal de la lengua 
compromiso del equipo médico para identificar los riesgos durante la anamnesis y poder intervenir oportunamente previniendo la aparición de la patología.

\section{BIBLIOGRAFÍA}

1. Pereira CM, Melo LG, Correa MM, Souza CA, Corrêa ME. Oral HPV infection in a bone marrow transplantation patient: a case report with atypical clinical presentation and unexpected outcome. Braz $\mathrm{J}$ Infect Dis. 2010;14(1):89-91.

2. Herrel NR, Johnson NL, Cameron JE, Leigh J, Hagensee ME. Development and validation of a HPV32 specific PCR assay. Virol J. 2009;27;6:90.

3. Reis HL, Ferreira DC, Forattini AG, Sou.za PG, Curvelo JA, Passos MR. Genital and oral human papillomavirus infection in a patient from the group of women who have sex with women. Clinics. 2010;65(12):13851385.

4. López-Jornet $\mathrm{P}$, Camacho-Alonso F, Berdugo L. Oral focal epithelial hyperplasia. N Y State Dent J. 2010;76(4):54-5.
5. Villanueva Álvarez-Santullano CA, Hernández-Núñez A, Castaño A, Miñano Medrano R, Córdoba Guijarro S, Borbujo Martínez J. Multifocal epithelial hyperplasia: a familiar case. An Pediatr (Barc). 2010;73(6):357-60.

6. Hashemipour MA, Shoryabi A, Adhami S, Mehrabizadeh Honarmand $H$. Extensive focal epithelial hyperplasia. Arch Iran Med. 2010;13(1):4852.

7. Faye M, Sissoko B, Gueye Diagne MC, Tamba Fall A, Diop F, Yam AA. Relationship between oral health status of parents and that of their children. Odontostomatol Trop. 2009;32(125):5-10.

8. Borborema-Santos CM, Castro MM, Santos PJ, Talhari S, Astolfi-Filho S.Oral focal epithelial hyperplasia: report of five cases. Braz Dent J. 2006;17(1):79-82.

9. Segura-Saint-Gerons R, Toro-Rojas M, CeballosSalobreña A, Aparicio-Soria JL, Fuentes-Vaamonde $\mathrm{H}$. Focal epithelial hyperplasia. A rare disease in our area. Med Oral Patol Oral Cir Bucal. 2005;10(2):12831.

10. Al-OsmanA, Perry JB, BirekC.Extensivepapillomatosis of the palate exhibiting epithelial dysplasia and HPV 16 gene expression in a renal transplant recipient. J Can Dent Assoc. 2006;72(4):331-4. 